\title{
8
}

\section{The Aboriginal Spring? Youth, Mobile Phones and Social Media in a Remote Aboriginal Community}

\author{
Kishan Kariippanon
}

\section{Introduction: The Field Site and the Project}

Awakened to the events of the Arab Spring, in which mobile phones and social media became the conduit for a revolution spearheaded by young people (Eltantawy and Wiest 2011), the potential for an 'Aboriginal Spring' sparked my interest in what I assumed were the temporal tools of an ever-changing technoscape (Appadurai 1988). The location of the research and its objectives emerged as a result of a social marketing project that attempted to address scabies with the help of emergent technology in a remote Aboriginal community. Rather than just regarding this technology as a convenient vehicle for public health messages, in the early stages of this project, I became interested in its meaning in this location. Similar to Hinkson's $(2002,2017)$ study of Walpiri new media, I was interested in how technology provides opportunities to extend and/or redefine sociality. This chapter explores the meanings embedded in mobile phones and social media for Yolngu youth in Yirkala in north-east Arnhem Land.

The aims of the study were crafted in consultation with multiple stakeholders. This involved a series of meetings with government agencies and the Aboriginal Medical Services Board and their public health team, 
and leaders of the families whose land I sought to enter to conduct my work. As a collective, we agreed that this research could be beneficial to the community by providing a clear understanding of the role of mobile phones and social media in Yolgnu society, and insight into the prevailing attitudes towards mobile phones and social media in the community, particularly among young people. To enable accessible and translatable findings for a broad audience, I would conduct ethnographic research exploring how emergent technologies belong in the community, and how they affect young people's kinship structure, social life and perceptions of community, including an account of how these technologies operate in their lives.

Through my attempts at learning the kinship system of the Yolngu people-that is, Dhuwa and Yirritja moieties and their respective clans-I arrived at an understanding that a randomised method of sampling would be culturally inappropriate. Through my interactions with cultural mentors, I became aware that my responsibility was to seek guidance from my maternal uncles (ngapipi), brothers (wawa and gathu) and fathers ( $b a p a)$ regarding the networks and individuals I could access for the study. Knowledge in this community, and in Aboriginal Australia more broadly, is often held by specific individuals. My adopted status determined my relationship to these individuals and enabled them to share some of their knowledge. Female members of this Arnhem Land community to whom I was connected via kin relationships were also interviewed to achieve a balanced view. These included senior, young and non-Indigenous women; the last worked closely with Yolngu families and were accorded the cultural authority needed to share their knowledge with me on specific aspects of the community.

The study participants held multiple roles in the community, were of various ages and held various kinship relationships to me. My engagement with young people was guided by their personal interests and I was sensitive to their autonomy. I did not expect them to feel obliged to me, even though I was regarded as their 'kin'. As the study focused on emergent technologies, and not Yolngu traditional knowledge systems, there was little need to intrude in culturally sensitive or inappropriate areas. The young people negotiated an intercultural or two-way approach (Marika and Isaacs 1995) to our engagement, balancing Yolngu law and non-Yolgnu culture. 
I quickly adapted to the new role of ethnographer, driving 'family' to and from funeral ceremonies or town, having the neighbours' children over for a play, being a water boy for one of the footy teams, setting up new mobile phone connections and producing music videos for teenagers. After three months in the community, I approached my next-door neighbour, a Traditional Owner, to ask if I could apply for the installation of wi-fi ADSL 2 broadband, which could be made available to the community. With his approval, the Telstra man arrived (there was only one contractor in the mining town) and my house was connected with 100 gigabyte ADSL 2+ broadband.

Soon thereafter, chairs showed up near my house, often on the veranda of my immediate neighbour, to access my wi-fi. Young people with mobile phones asked me for the wi-fi password and then added me as their friend on Facebook. They 'suggested' and 'introduced' other friends or family from different communities to extend their 'friend list' on Facebook. The wi-fi connection had anywhere between three and 10 users at a time. Depending on the ability of their phones' connection, and their proximity to my house, some young people were able to surf the internet from the comfort of their own homes.

Within two months, several mobile devices such as iPhones, Samsung flip phones and smartphones were joined by Android tablets as the arsenal of new technology in the community began to accumulate. Three months later, a brand new Hewlett Packard laptop was purchased by a neighbouring family who streamed movies and YouTube videos and downloaded music. As I began hearing different songs, I observed the transformative power of technology; however, it remained a technology that was wrapped in Yolngu culture, as I shall discuss throughout this chapter. The variety of expression and choices made via laptop, phone and the internet truly amazed me.

\section{Learning to Observe Media and Emergent Technology in Context}

Dark nights in the backyard were now lit by glowing computer or mobile phone screens, with shirtless men and children cooling off as they enjoyed a movie. Groups of young people started 'sitting about' instead of (or perhaps as well as) 'walkin about at night' (Senior and Chenall 2008) to find a boyfriend or girlfriend, a Yolngu version of the 'Netflix and 
chill' culture now prevalent among urban non-Indigenous youth (Griffith 2015). As my face became more familiar in the Gove Peninsula, I reached out through online and offline networks to connect with other youth. I looked forward to the biweekly footy training sessions in Yirrkala, of which I made a video clip using an iPhone 4 and iMovie on my MacBook Air computer. The head coach got all the players together and said: ' $[\mathrm{K}]$ wants to take photos and videos to make a music video, if anyone doesn't like it just tell him straight up, manymak [good or ok]?!'

That was an excellent icebreaker. The men were somewhat shy in front of the camera and I was careful not to overstay my welcome. It had only to be a two-minute clip when finished, and about 20 minutes of raw footage was estimated to be sufficient. The finished product was not a music video with a health message about drink driving or domestic violence (which are some of the most common forms of externally produced films in the community). Instead, it was a lens of how I experienced the team-albeit a somewhat crude and simplistic one. The music video of footy playerssome with boots, some barefoot, a few sockless—was a simple artistic portrayal that captured something of their lives in the context of the football game and their dedication to training and winning.

Just before our Thursday training at $5.30 \mathrm{pm}$, I brought my laptop to share the video and sought feedback for further editing. Johnny swiftly took over, showing me how to use bluetooth to send the video to his LG smartphone. The men were encouraging and supportive, showing their appreciation of my efforts through sharing the clip. Each bluetoothenabled phone that downloaded the video showed up on my laptop's screen with its nickname or series of four numbers ${ }^{1}$ as the players trickled in for practice and started putting on their boots. ${ }^{2}$ Those who had a mobile phone 'bluetoothed' the video to each other, speeding up the process of sharing, behaviour that was expected in the community.

The challenges of life in a communal society with few resources and little employment made mobile phones transient. Despite their competent use of technology, the poverty of young people in this intercultural setting meant that continuing ownership of personal tools was imaginable only for a fortunate few. Demands for sharing meant that no one device stayed in the hands of one owner only.

1 Bluetooth ID.

2 Sports shoes with studs or 'stops' on the outer sole. 
The Android tablets and mobile phones without protective covers eventually disintegrated in the hands of children who asked and received without hesitation. The new laptop met the concrete floor at an angle that told a story of anger and jealousy after an argument between a young woman and man. The technology was swiftly but tragically reduced to plastic and green wafers within three months.

\section{Social Media or Social Trap?}

In this remote intercultural setting, Facebook and YouTube revealed a different side of Aboriginal life. Only a few years ago, I had hoped that social media, especially Facebook and Twitter, would bring an 'Aboriginal Spring' (Eltantawy and Wiest 2011; Carlson and Frazer 2016), filling the vacuum of Western knowledge with information while simultaneously providing a means for Aboriginal people to voice their disapproval at the oppression wrought by the dominant culture in a way that might be broadly heard and used to shame unjust political structures (Bevir 1999).

Gradually, I began to find patterns in the social life of social media and mobile phones through discussions, interviews, observations and informal talks with a wide variety of individuals. My assumptions that these new technologies were the reincarnation of the khayu (message stick) or the lippa (dugout canoe), which had occurred in earlier centuries as a result of intercultural technological exchange between Indigenous nations and Macassan traders (Clark and May 2013), was nothing but a figment of my post-colonial imagination. Rather than being a major social innovation and encompassing radical change, social media in this remote Aboriginal community appeared to intensify pre-existing practices, both good and bad.

During my study, I systematically deconstructed and discarded the lens I arrived with and gradually developed a more accurate understanding of the effects of social media and mobile phones in this remote community. In this political and socioeconomic context, the 'spear' of technology used in the 'Arab Spring' (Eltantawy and Wiest 2011), and the blurring of colonial binaries as discussed by Tofighian (2013), seemed doubleedged, distorting both the stability of the kinship system and the control of traditional law. 
The kinship laws of Gurrutu and societal order are dictated to all living and inanimate beings (Keen 1990; Morphy and Morphy 1984). There is a place for everything and life is a prescribed existence in the Yolngu world. However, there was no place for social media and mobile phones: they arrived and gained a presence before laws and theories of their use could be formulated. Was this period of ebb and flow of negotiations between culture and the emergent technology producing a social trap? According to my interviewees, the path of prioritising individual 'ego' over the collective (clan hood) through the aid of technology risked creating discord among clans and families that could extend to individuals born from 'wrong way'3 relationships (Burbank 1994) —in other words, a social trap.

Three o'clock in the morning was a typically youthful time to 'hang out' with peers. After the hustle and bustle of the local pub had dispersed into private homes or the poorly lit park, all was quiet for reflection. My brother and I placed ourselves cross-legged on a mat while our uncle (younger than I, chronologically) sat on a chair. My brother explained as my uncle nodded:

Brother, this phone here is Yirritja, belongs to our uncle's moiety. Facebook is Dhuwa. The phone is Yirritja because it is a new tool and Yirritja have since Mangatharra (Macassan) times been the owner of new things. Facebook is Dhuwa; without it, the phone is only half.

This points to the complimentary nature of the kinship system: it could both accommodate the adoption of new technologies and recognise them as interrelated. Through the kinship system, the internet and social media could be used instrumentally to extend existing patterns of communication and kinship.

This extension was explained by Peter, an Indigenous footy coach. He found the use of Facebook highly appropriate and convenient to communicate with his players and their extended families. He said: 'The main role for the Facebook page [is] to announce training and match times, scores and draws'. He also said: 'it's the photos is what they love'.

A more complex scenario was presented by Josephine, who reflected on the use of Facebook as an online point of contact, a highly useful tool when vast distances stood between homelands and communities. However, she had seen videos of youths fighting that had been filmed by an onlooker.

3 Yolngu marriages that were contracted between romantic partners, suggesting 'incest' and a breaking of the traditional betrothal law. 
She 'asked them, why do you have these videos? It's real'. She wanted the young boys to consider their actions: 'two people are fighting, they're hurting each other'. But, to her dismay, they seemed to lack empathy and respect. They said: 'Oh just for fun'. She looked at me and said, 'I think it is to tease the family of the boy who lost the fight', a form of cyberbullying amplified to discomfort a whole family unit or clan.

Susan, a mother of two teenage boys, spoke about the use of social media and mobile phones. Stressing the importance of brotherly acceptance, she said: 'For the boys it's proving yourself to your brothers, everybody, your group, your friends, especially your brothers'. The ability to defend yourself and intimidate peers, and to protect the honour of your family, was a pathway to self-discovery and identity formation for many young men. With the advent of new technologies, such conflict could continue on Facebook, YouTube or Divas Chat. Physical control of disputes by other relatives and allies no longer seemed necessary, or possible, and what often began as harmless teenage projects of self-exploration escalated into inter-clan arguments. And, as the new tool was used to communicate news in the community, it increased the spread of conflict through the reposting of screenshots of 'swearing' and 'jealousing' (Burbank 1994).

Subjected to the practice of 'demand sharing' (Peterson 1993; Altman 2011), the life cycle of mobile phones and phone numbers ranged from one month to less than a year. 'My workers go through phones as I go through clothes ... regardless of cheaper phones or more expensive', said Sean, a non-Aboriginal health worker. (I had asked whether a more expensive phone would have a longer life and continuity with its owner.) Sean's Yolngu team endorsed the transient nature of mobile phones and concept of ownership in the community. Three men with families and leadership roles in the community, they glanced at me from time to time as a sign of agreement with Sean's comments.

During my study, I observed that only young people with a secondary education were able or empowered to avoid the pressure of sharing their phone or surrendering it to a more powerful or senior relative. 'That's right, they're stepping out', said Cindy, an Aboriginal mother who confirmed my thoughts. She continued:

But they are not using it the way you do. They are looking for accolade within their peer group. They are not necessarily looking for accolade within the higher Gurrutu (kinship) structure, and that's just a normal teenage behaviour. 


\section{The Effects of Social Media Use on Youth}

According to Subrahmanyam and Greenfield (2008), non-Indigenous youth use communication tools to reinforce existing relationships, both with friends and romantic partners. When compared to their offline worlds, social networking sites like Facebook mislead the young person into thinking that they can find privacy online. This encourages exploration and risk-taking: the young person believes their actions will not be discovered by their outside social networks and family. Yolngu youth share this misinformed perception of relative privacy and personal space in the online world. Regarding social media, boyd (2007) cautioned that 'words and photos can be copied or altered and shared with others who are not the intended audiences, thereby creating an avenue for cyberbullying'.

Subrahmanyam and Greenfield $(2008,124)$ draw on Hill's $(1983,124)$ claim that 'adolescent behaviour is best understood in terms of the key developmental tasks - identity, autonomy, intimacy, and sexuality-and the variables, such as gender and social class, that influence them' to propose that:

Today's youth media technologies [are] an important social variable and that physical and virtual worlds are psychologically connected; consequently, the virtual world serves as a playing ground for developmental issues from the physical world such as identity and sexuality. (Hill 1983, 525)

This proposition is relevant in the context of this remote community. This became evident in interviewees' contributions that showed how extreme behaviour portrayed on social media played out in community life. The mother of a girl in her teens complained: 'Who writes that shit on Facebook'. This woman, who generously assisted me in the study, urged me to look closely at the popular social media site and said: 'You'll notice that on Facebook, with their comments, you notice the "statuses" that young people write and you wonder, gee, where their heads are ... you know even at home'. This mother wanted me to understand that homes and family could mean very little to a vulnerable young person. They did not have to be physically isolated from familiar surroundings in the community to feel emotionally and socially isolated. Being surrounded by family did not always result in feelings of solidarity and subsidiarity. While mental and emotional isolation could build resilience in a supportive environment, in a resource-poor setting, it could cause long-term distress. 
Clerkin, Smith and Hames $(2013,525)$ assert that the internet allows 'children and adolescents to fulfil critical needs of social interactions, self-disclosure and identity exploration'. According to Forest and Wood (2012), for young people with low self-esteem, Facebook can be an attractive means of disclosing personal information. Facebook has the potential for positive outcomes for those who struggle interpersonally; however, when used ineffectively, it can confer a negative long-term vulnerability (Forest and Wood 2012). What constitutes ineffective uses of Facebook or other social media sites? Is it the use of the tool or the conflict between the tool and Yolngu culture that creates a (potential) social trap? One of my interviewees, parodying the mannerism of a young person, said:

You've got an iPhone and I've just got a flip phone. Miyalk (women), giddy (belonging or things), rrupiah (money). Even work. You think you're good because you've got djama (work)?

Here we see a young person blaming his peer for trying to stand out from the crowd by owning a piece of technology, engaging in intimate relationships and maintaining employment that opened up a world of material possessions, resulting in a higher social status among kin. It is a put down for acting 'white' and subscribing to the ways of the Other (see also Burbank 2011, 129).

In Yolngu society, the notion of work, income and ownership of material objects may not be linked to the same sense of achievement as in Western societies. This disconnect from the socioeconomic structure of the larger society is accompanied by young people's growing disregard for the ethos that accompanies the Yolngu kinship system. The kinship system, which provides the grounds for demand sharing and reciprocity, has long militated against the development of status and wealth difference. Social media, when combined with the rise of Indigenous corporatisation (Rowse 2012) and resultant resentment and discord, has created a platform for discourses that appear to be pushing this ethic aside, at least for the youth of this community.

Muise, Christofides and Desmarais (2009) found that high-frequency use of Facebook among young couples predicted jealousy-related feelings and behaviours, such as the regular checking of a partner's profile and suspicion of their online activity. Susan had paid close attention to the dynamics of mobile phone and social media use in her community for almost 20 years. She reflected on some of the challenges of seamless communication in 
a community where polygyny was the normative behaviour until the influence of Christian missionaries diminished its practice. She connected domestic violence to the use of mobile phones and social media, as they could facilitate infidelity:

Because they jealous and they thought that you'll meet someone, it can happen to anyone, any age. Before it was opportunistic, now social media and mobile phones make it much more manageable.

Many young people form relationships and attempt to move to the next level of intimacy by swapping Facebook passwords; some even share a single Facebook profile as a means of precluding infidelity. However, a falling out in the relationship can threaten this trust, presenting the opportunity for an aggrieved partner to post intimate material and photographs online as a form of jealousy porn.

Amid their exploration of identity, sexuality and relationships, young people simultaneously search for reassurance. According to Clerkin, Smith and Hames (2013), the relationship between Facebook reassurance seeking and self-esteem is heavily implicated in the genesis of two interpersonally generated feelings: 'thwarted belongingness' (e.g. I am alone) and 'perceived burdensomeness' (e.g. I am a burden) (Van Orden et al. 2010, quoted in Clerkin, Smith and Hames 2013, 526).

A combination of 'thwarted belongingness' and 'perceived burdensomeness' has the potential to be damaging. These emotionally laden cognitions may, according to Van Orden et al. (2010) and Clerkin, Smith and Hames (2013), produce the desire for suicide. Evraire and Dozois (2011) conclude that negative online feedback as a result of excessive reassuranceseeking is detrimental to the maintenance of healthy interpersonal relationships, and Sowislo and Orth (2013) assert that young people's Facebook status updates reflect their 'offline' selves and can signal that the path into depression is not far away.

What, then, were the effects of social media on youth in this remote Indigenous setting? Here too, Facebook hosted constant calls for reassurance and attention. YouTube became a platform on which videos of street fights were uploaded and endlessly viewed. Young people trying to drown out the noise and frustrations of life in overcrowded houses turned away from face-to-face interactions and searched for meaningful relationships via social media. A perceived lack of attention and reassurance could be countered with threats of suicide. Several of the people I spoke to 
suggested that such behaviour had become the norm, but most also said that if someone was serious about taking their own life, they would not talk about it openly.

To increase consumption and profit, social media and mobile phones engage in a continuous cycle of improvement and innovation. Inserted into a society still reeling from its colonial history and resultant dissent and conflict, these technologies deeply influenced Yolngu youth who, due their adolescent life stage, were inherently vulnerability (e.g. Konner 2010; Schlegel and Hewlett 2011). Through the use of social media, young people already challenged with low self-esteem and social isolation became entrapped in the digital economy of the future. Capitalist values of competition and subjugation became interwoven with old behaviours of clan hood, power and domination. A clear example of how damaging these so-called technological improvements could be to remote Aboriginal youth emerged during an interview with a young man. He told me about a pornography site that was able to function with low data streaming. $\mathrm{He}$ was concerned about its accessibility, as even the slowest Telstra connections and Samsung flip phones could access the site. He mentioned a couple's private media that was posted on the site and said:

If her brother has seen that, who knows what the consequences can be. Back in the day they'd probably get bashed. Maybe they were even wrong skin [incorrect marriage partners].

This technology-induced social disruption has deep implications for the healthy development of youth and their relationships in north-east Arnhem Land.

\section{Negotiating a Globalised Identity within a Yolngu Framework}

The plurality of lifestyles (Kral 2014) experienced by Indigenous youth seems contradictory to the image of the 'noble' non-materialistic Aboriginal person embedded in mainstream Australian society (Rowse 2012). Appadurai $(1996,65)$ has encouraged anthropologists to 'come in from the cold and face the challenge of making a contribution to cultural studies without the benefit of its previous principal source of leveragesightings of the savage'. Indigenous people are both inspired and led by their culture; however, in most cases, they will critically reflect on their 
practices and relationships (Kariippanon et al. 2015) to create a better life. The use of technology in this process of reflection and action has been clarified through the work of Carlson and Frazer (2016).

Young people have redefined their value system as a result of globalisation in a post-colonial economic order. Their visual documentation of their alcohol consumption and fights, as well as peer reactions to these, on social media have turned culturally unacceptable behaviours into positive or at least normalised behaviours (Beullens and Schepers 2013). It was no coincidence that increasing levels of violence occurred at the same time as Aboriginal youths gained access to mobile phones and social media (Langton 2008; Clark and Augoustinos 2015). This can be attributed, at least in part, to the internalisation of colonial oppression and the experiences of social and economic marginalisation (Rowse 2012). Emerging in an era of self-determination, the new technology has enabled the amplification of these experiences.

For Yolngu youth with positive support systems, culture only ever acts as a guide (Deger 2006). According to my interviewees, an example of a positive support system is one in which young men have a consistent male presence in the home and experience fulfilment of kinship obligations towards one another. But culture can be changed by external influences, including those designed to perform such functions. For example, Moreno et al. (2013) have suggested that Facebook was constructed to influence user attitudes, intentions and behaviours. Could Yolngu youth be more influenced by Facebook than by their culturally grounded upbringing? It is possible that, in the face of unfulfilled relationships and the absence of positive role models, young people have become more vulnerable to the influence of such technologies. Facebook itself may have amplified the power of the dominant discourse and dominant culture on minorities, acting as a commercial engine for capitalist assimilation, creating a consumer-centric culture amid Aboriginal ways of being.

The 'Aboriginal Protector' or colonial master-a figure of dominance and control-has been reincarnated in social media through monitoring and surveillance, internalised by Yolngu youth who perform surveillance activities (Millie, Darvell and White 2011) on Facebook and Divas Chat. Unlike the findings from research conducted with non-Indigenous participants, self-esteem did not significantly predict frequent partner monitoring for Indigenous youth on Facebook and Divas Chat (Fox and Warber 2013; Senior, Helmer and Chenhall 2017). It seems that the 
oppressive attitudes of colonialists have been normalised and entrenched in the lives of Aboriginal people living in low socioeconomic conditions (Langton 2008). This claim is substantiated with findings of 'online public fighting' and 'jealousing' by Senior, Helmer and Chenhall (2017).

During my time with Yolngu people, I observed that, while Aboriginal identity remained within its customary boundaries, the alteration of traditional practices, often in economic exchanges, had transformed the new technology into a double-edged spear. The individualisation of Aboriginal youth, as observed in their use of a new kind of communication technology, had resulted in the formation of bicultural identities within an Indigenous structure. Martin (quoted in Rowse 2012, 116) explained that: 'There is no such thing as an autonomous arena of Indigenous values and practices, rather there is a contested intercultural field of transforming and transformed practices and values'.

The redrawing of the borders between Indigenous youth and globalised youth culture-the appropriation of hip hop alongside the sounds of the yidaki (didgeridoo), the desire to use the same communication tools as their non-Indigenous peers - did not signal the intention to defy or undermine Yolngu culture, but to embrace modernity. Like challenging the power and bureaucracy of Indigenous elders and Traditional Owners, this was a natural phase of identity exploration by Indigenous youth (see also Chapter 3, this volume).

The understanding that mobile phones and social media—unlike tobacco, dugout canoes and other Macassan or Commonwealth commodities-are not governed or monopolised by a gerontocracy, allowed Indigenous youth to achieve a level of autonomy from their elders: a measure of liberation from the confines of cultural conservatism. Facebook and Divas Chat supported them in their engagement with another reality, one beyond the constraints of remote public housing: cramped, unfurnished and lacking in privacy. According to Senior (2003) and Senior and Chenhall (2012), these are essential features for positive youth development. Mobile phones and social media appear to have been adopted, at least in part, as opportunities to improvise, to create order and control, and to access resources in the hope of eventually beating the internal and external forces of inequality. For example, Joe said:

There's not whole lot for youth to be doing [here]. In the cities and stuff, unless they feel unsafe, there are plenty of things for people to be doing unlike in this region. 
However, Vaarzon-Morel (2014), in her study of technology and social relations among Walpiri, reminds us that tensions in this technology have the potential to exacerbate and intensify existing social problems.

\section{Conclusion}

The use of mobile phones and social media at Yirkala is a doubleedged sword. At the same time as creating opportunities, they threaten to destablise and undermine important aspects of young people's lives. The need and ability for young people to explore their identity, strive for autonomy and engage in the globalised world has enabled a process of creating and negotiating bicultural identities, furthering the development of Aboriginal modernity. The opportunity for young people to claim a place in the nation's economy and to be heard as part of dominant discourses, regardless of status and power, has been reinforced by the accessibility of online tools and excellent mobile phone coverage. Conversely, the tensions that arise from the use of social media threaten the experience of youth as they explore sexuality and intimate partner relationships. Equally, the internalisation of old power structures of community elders, Christian missions and Aboriginal protectors has created a practice of surveillance and suspicion that threatens to stifle young people's freedom of expression and innovation.

\section{References}

Appadurai, A. 1988. The Social Life of Things: Commodities in Cultural Perspective. Cambridge: Cambridge University Press.

Appadurai, A. 1996. Modernity at Large: Cultural Dimensions of Globalization. Minneapolis: University of Minnesota Press.

Altman, J. 2011. 'A Genealogy of "Demand Sharing": From Pure Anthropology to Public Policy'. In Ethnography and the Production of Anthropological Knowledge: Essays in Honour of Nicolas Peterson, edited by Y. Musharbash and M. Barber, 209-22. Canberra: ANU E Press. doi.org/10.22459/EPAK.03.2011.13.

Beullens, K. and A. Schepers. 2013. 'Display of Alcohol Use on Facebook: A Content Analysis'. Cyberpsychology, Behavior, and Social Networking 16 (7), 497-503. doi.org/10.1089/cyber.2013.0044. 
Bevir, M. 1999. 'Foucault, Power, and Institutions'. Political Studies 47 (2): 34559. doi.org/10.1111/1467-9248.00204.

boyd, d. 2007. 'Social Network Sites: Public, Private, or What'. Knowledge Tree 13 (1): 1-7.

Burbank, V. K. 1994. Fighting Women: Anger and Aggression in Aboriginal Australia. Berkley: University of California Press.

Burbank, V. K. 2011. An Ethnography of Stress: The Social Determinants of Health in Aboriginal Australia. New York: Palgrave Macmillan. doi.org/10.1057/ 9780230117228.

Carlson, B. and R. Frazer. 2016. 'Indigenous Activism and Social Media: A Global Response to \#SOSBLAKAUSTRALIA'. In Negotiating Digital Citizenship: Control, Contest and Culture, edited by A. McCosker, S. Vivienne and A. Johns, 115-30. Lanham: Rowman \& Littlefield.

Clark, M. and S. K. May. 2013. Macassan History and Heritage: Journeys, Encounters and Influences. Canberra: ANU E Press. doi.org/10.22459/MHH.06.2013.

Clark, Y. and M. Augoustinos. 2015. 'What's in a Name? Lateral Violence within the Aboriginal Community in Adelaide, South Australia'. Office Bearers of the APS College Of Community Psychologists 27(2): 19.

Clerkin, E. M., A. R. Smith and J. L. Hames. 2013. 'The Interpersonal Effects of Facebook Reassurance Seeking'. Journal of Affective Disorders 151 (2): 52530. doi.org/10.1016/j.jad.2013.06.038.

Deger, J. 2006. Shimmering Screens: Making Media in an Aboriginal Community. Minnesota: University of Minnesota Press.

Eltantawy, N. and J. B. Wiest. 2011. 'The Arab Spring. Social Media in the Egyptian Revolution: Reconsidering Resource Mobilization Theory'. International Journal of Communication 5: 18.

Evraire, L. E. and D. J. Dozois. 2011. 'An Integrative Model of Excessive Reassurance Seeking and Negative Feedback Seeking in the Development and Maintenance Of Depression'. Clinical Psychology Review 31(8): 1291-303. doi.org/10.1016/j.cpr.2011.07.014.

Forest, A. L. and J. V. Wood. 2012. 'When Social Networking Is Not Working Individuals with Low Self-Esteem Recognize but Do Not Reap the Benefits of Self-Disclosure on Facebook'. Psychological Science 23 (3): 1-8. doi.org/ $10.1177 / 0956797611429709$. 
Fox, J. and K. M. Warber. 2013. 'Romantic Relationship Development in the Age of Facebook: An Exploratory Study of Emerging Adults' Perception, Motives and Behaviors'. Cyberpsychology, Behavior, and Social Networking 16 (1): 3-7. doi.org/10.1089/cyber.2012.0288.

Griffith, M. E. 2015. 'Downgraded to Netflix and Chill: Freedom of Expression and the Chilling Effect on User-Generated Content in Europe'. Columbia Journal of European Law 22: 355.

Hill, J. 1983. 'Early Adolescence: A Framework'. Journal of Early Adolescence 3 (1): 1-21. doi.org/10.1177/027243168331002.

Hinkson, M. 2002. 'New Media Projects at Yuendumu: Inter-Cultural Engagement and Self-Determination in an Era of Accelerated Globalization'. Continuum 16 (2): 201-20. doi.org/10.1080/10304310220138769.

Hinkson, M. 2017. 'Beyond Assimilation and Refusal: A Warlpiri Perspective on the Politics of Recognition'. Postcolonial Studies 20 (1): 86-100. doi.org/ 10.1080/13688790.2017.1334281.

Kariippanon, K. A., D. Garrawirtja, K. Senior, P. Kalfadellis, V. Narayan and B. McCoy. 2015. 'Ethnography and Filmmaking for Indigenous Anti-Tobacco Social Marketing'. In World Social Marketing Conference Sydney 2015, 21-23. Lichfield, UK: Fuse Events.

Keen, I. 1990. 'Images of Reproduction in the Yolngu Madayin Ceremony'. Australian Journal of Anthropology 1 (2-3): 192-207. doi.org/10.1111/j.17576547.1990.tb00383.x.

Konner, M. 2010. The Evolution of Childhood: Relationships, Emotion, Mind. Cambridge, MA: Harvard University Press.

Kral, I. 2014. 'Shifting Perceptions, Shifting Identities: Communication Technologies and the Altered Social, Cultural and Linguistic Ecology in a Remote Indigenous Context'. Australian Journal of Anthropology 25 (2): 171-89. doi.org/10.1111/taja.12087.

Langton, M. 2008. 'The End Of "Big Men” Politics'. Griffith Review (22): 48.

Marika, W. and J. Isaacs. 1995. Wandjuk Marika: Life Story. St Lucia: University of Queensland Press.

Millie, J., S. P. Darvell and K. M. White. 2011. 'Facebook Tells Me So: Applying the Theory of Planned Behavior to Understand Partner-Monitoring Behavior On Facebook'. Cyberpsychology, Behavior, and Social Networking 14 (12): 717-22. doi.org/10.1089/cyber.2011.0035. 
Moreno, M. A., R. Kota, S. Schoohs and J. M. Whitehill. 2013. 'The Facebook Influence Model: A Concept Mapping Approach'. Cyberpsychology, Behavior, and Social Networking 16 (7): 504-11. doi.org/10.1089/cyber.2013.0025.

Morphy, H. and F. Morphy. 1984. 'The "Myths" of Ngalakan History: Ideology and Images of the Past in Northern Australia'. Royal Anthropological Institute of Great Britain and Ireland 19 (3): 459-78. doi.org/10.2307/2802183.

Muise, A., E. Christofides and S. Desmarais. 2009. 'More Information than You Ever Wanted: Does Facebook Bring Out the Green-Eyed Monster of Jealousy?' CyberPsychology \& Behavior 12 (4): 441-44. doi.org/10.1089/cpb.2008.0263.

Peterson, N. 1993. 'Demand Sharing: Reciprocity and the Pressure for Generosity among Foragers'. American Anthropologist 95 (4): 860-74. doi.org/10.1525/aa. 1993.95.4.02a00050.

Rowse, T. 2012. Rethinking Social Justice: From "Peoples" to "Populations". Canberra: Aboriginal Studies Press.

Schlegel, A. and B. Hewlett. 2011. 'Contributing of Anthropology to the Study of Adolescence'. Journal of Research on Adolescence 21(1): 281-89. doi.org/ 10.1111/j.1532-7795.2010.00729.x.

Senior, K. 2003. 'A Gudbala Laif? Health and Wellbeing in a Remote Aboriginal Community-What Are the Problems and Where Lies Responsibility?' $\mathrm{PhD}$ thesis, The Australian National University, Canberra.

Senior, K. and R. Chenhall. 2008. 'Walkin' About at Night': The Background to Teenage Pregnancy in a Remote Aboriginal Community'. Journal of Youth Studies 11 (3): 269-81. doi.org/10.1080/13676260801946449.

Senior, K. and R. Chenhall. 2012. 'Boyfriends, Babies and Basketball: Present Lives and Future Aspirations of Young Women in a Remote Australian Aboriginal Community'. Journal of Youth Studies 15 (3): 369-88. doi.org/10.1080/ 13676261.2012.663890.

Senior, K., H. Helmer and R. Chenhall. 2017. ' “As Long as He’s Coming Home to Me': Vulnerability, Jealousy and Violence in Young People's Relationships in Remote, Rural and Regional Australia'. Health Sociology Review 26 (2): 204-18. doi.org/10.1080/14461242.2016.1157697.

Sowislo, J. F and U. Orth. 2013. 'Does Low Self-Esteem Predict Depression and Anxiety? A Meta-Analysis of Longitudinal Studies'. Psychological Bulletin 139 (1): 213. doi.org/10.1037/a0028931. 
Subrahmanyam, K. and P. Greenfield. 2008. 'Online Communication and Adolescent Relationships'. Future of Children 18 (1): 119-46. doi.org/10.1353/ foc. 0.0006 .

Tofighian, N. 2013. Blurring the Colonial Binary: Turn-of-the-Century Transnational Entertainment in Southeast Asia. Stockholm: University of Stockholm.

Vaarzon-Morel, P. 2014. 'Pointing the Phone: Transforming Technology and Social Relations among Walpiri'. Australian Journal of Anthropology 25(2): 239-55. doi.org/10.1111/taja.12091.

Van Orden, K. A., T. K. Witte, K. C. Cukrowicz, S. R. Braithwaite, E. A. Selby and T. E. Joiner Jr. 2010. 'The Interpersonal Theory of Suicide'. Psychological Review 117 (2): 575. doi.org/10.1037/a0018697. 
This text is taken from Indigenous Australian Youth Futures: Living the Social Determinants of Health, edited by Kate Senior, Richard Chenhall and Victoria Burbank, published 2021 by ANU Press, The Australian National University, Canberra, Australia.

doi.org/10.22459/IAYF.2021.08 